Acta Crystallographica Section E

Structure Reports

Online

ISSN 1600-5368

\section{María Jesús Diánez, María Dolores Estrada and Simeón Pérez-Garrido*}

Instituto de Ciencias de Materiales de Sevilla and Departamento de Física de la Materia Condensada, CSIC-Universidad de Sevilla, Apartado 1065, 41080 Sevilla, Spain

Correspondence e-mail: dianez@us.es

\section{Key indicators}

Single-crystal X-ray study

$T=293 \mathrm{~K}$

Mean $\sigma(\mathrm{C}-\mathrm{C})=0.009 \AA$

$R$ factor $=0.046$

$w R$ factor $=0.166$

Data-to-parameter ratio $=8.8$

For details of how these key indicators were automatically derived from the article, see http://journals.iucr.org/e.
(C) 2006 International Union of Crystallography All rights reserved

\title{
(1E,3E)-4-(Tetra-O-acetyl-D-arabino-tetritol-1-yl)- 1-(4-tolyl)-1,2-diaza-1,3-butadiene
}

In the title compound, $\mathrm{C}_{21} \mathrm{H}_{26} \mathrm{~N}_{2} \mathrm{O}_{8}$, the configurations of the three chiral centres are known from the synthesis, corresponding to a D-arabino configuration. Both double bonds show the $E$ configuration in the solid state. Packing of the molecules is governed by normal van der Waals contacts.

\section{Comment}

Following current work on asymmetric synthesis from carbohydrates, Avalos et al. (1995) developed a general synthesis of sugar 1,2-diaza-1,3-butadienes. The title compound, (I), was prepared by treatment of D-mannose with aryl hydrazines, and the corresponding aryl hydrazones were readily obtained. Further conventional acetylation and thermal 1,4-elimination gave 1-aryl-1,2-diaza-1,3-butadienes. In all cases, aryl diazabutadienes were coloured crystalline compounds and could be stored for long periods without appreciable decomposition.

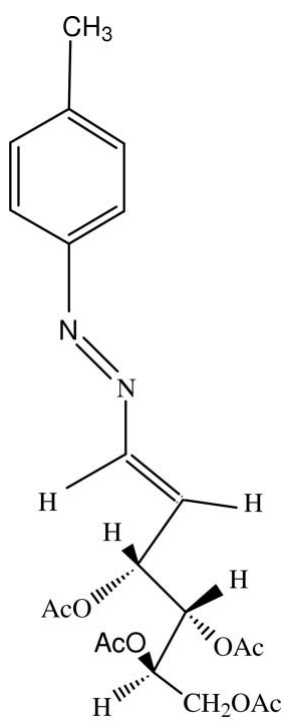

(I)
Received 23 May 2006 Accepted 6 June 2006
An X-ray investigation of compound (I) was carried out in order to elucidate unequivocally the molecular conformation of (I) in the solid state. A perspective view of (I) with the atom-numbering scheme is shown in Fig. 1.

Prinicpal geometric parameters are given in Table 1. Both double bonds exist in the $E$ configuration in the solid state.

The arabino chain $(\mathrm{C} 4 / \mathrm{C} 41 / \mathrm{C} 42 / \mathrm{C} 43)$ is planar, with the terminal atom $\mathrm{C} 44$ having a maximum deviation from the least-squares plane of 0.017 (5) $\AA$. The configurations of the chiral centres $\mathrm{C} 41, \mathrm{C} 42$ and $\mathrm{C} 43$ are $R, S$ and $R$, respectively. The packing of the molecules is governed by normal van der Waals contacts. 


\section{Experimental}

The title compound was synthesized from D-mannose (4-methylphenyl) hydrazone, according to the procedure of Avalos et al. (1995). Compound (I) was recrystallized from ethanol-water.

\section{Crystal data}

$\mathrm{C}_{21} \mathrm{H}_{26} \mathrm{~N}_{2} \mathrm{O}_{8}$

$M_{r}=434.44$

Orthorhombic, $P 2_{1} 2_{1} 2_{1}$

$a=14.065$ (1) ^

$b=30.189(2) \AA$

$c=5.6414(3) \AA$

$V=2395.4(3) \AA^{3}$

$$
Z=4
$$

$D_{x}=1.205 \mathrm{Mg} \mathrm{m}^{-3}$

Mo $K \alpha$ radiation

$\mu=0.09 \mathrm{~mm}^{-1}$

$T=293(2) \mathrm{K}$

Prism, light brown

$0.32 \times 0.28 \times 0.16 \mathrm{~mm}$

\section{Data collection}

Enraf-Nonius CAD-4

diffractometer

$\omega / 2 \theta$ scans

Absorption correction: none

5210 measured reflections

2458 independent reflections

$$
\begin{aligned}
& 1196 \text { reflections with } I>2 \sigma(I) \\
& R_{\text {int }}=0.027 \\
& \theta_{\max }=25^{\circ} \\
& 3 \text { standard reflections } \\
& \text { frequency: } 60 \text { min } \\
& \text { intensity decay: } 6 \%
\end{aligned}
$$

\section{Refinement}

Refinement on $F^{2}$

$R\left[F^{2}>2 \sigma\left(F^{2}\right)\right]=0.046$

$w R\left(F^{2}\right)=0.166$

$S=0.97$

2458 reflections

280 parameters

$$
\begin{gathered}
w=1 /\left[\sigma^{2}\left(F_{\mathrm{o}}{ }^{2}\right)+(0.0855 P)^{2}\right. \\
+0.3134 P] \\
\text { where } P=\left(F_{\mathrm{o}}{ }^{2}+2 F_{\mathrm{c}}{ }^{2}\right) / 3 \\
(\Delta / \sigma)_{\max }=0.009 \\
\Delta \rho_{\max }=0.22 \mathrm{e} \AA^{-3} \\
\Delta \rho_{\min }=-0.17 \mathrm{e}^{-3}
\end{gathered}
$$

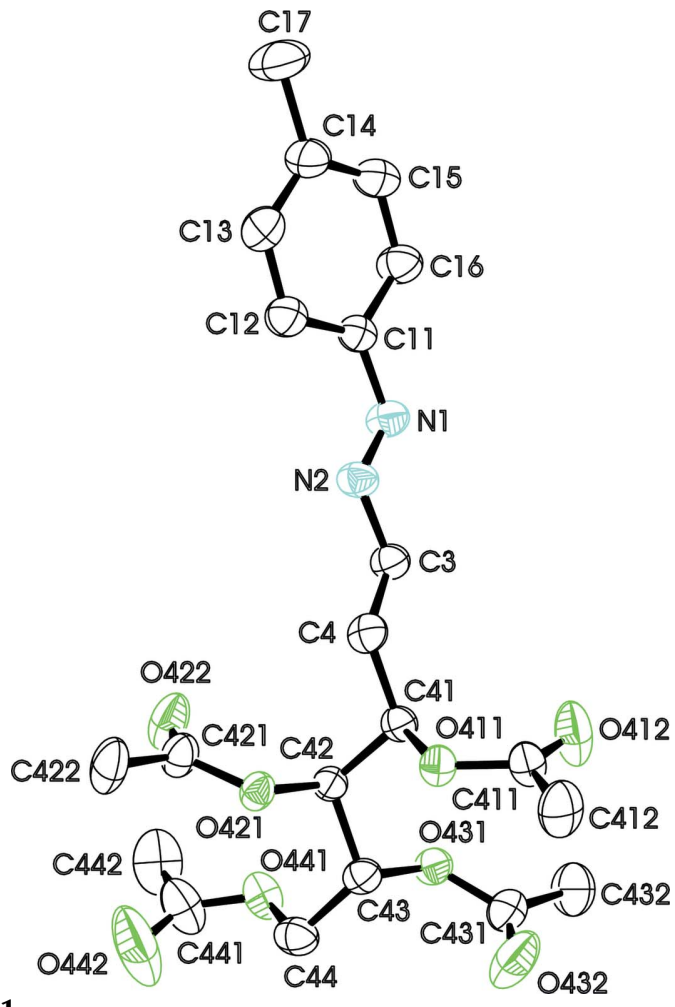

Figure 1

A view of the molecular structure of (I), showing the atomic numbering scheme. Displacement ellipsoids are drawn at the $30 \%$ probability level. For clarity, only the most important $\mathrm{H}$ atoms are shown.

used to prepare material for publication: SHELXL97 and PARST (Nardelli, 1995).

The authors thank Dr Palacios, Universidad de Extremadura, Badajoz, Spain, for supplying the crystal, and the Junta de Andalucía for financial support.

\section{References}

Avalos, M., Babiano, R., Cintas, P., Jimenez, J. L., Palacios, J. C. \& Sanchez, J. B. (1995). Tetrahedron Asymmetry, 6, 954-956.

Burla, M. C., Camalli, M., Carrozzini, B., Cascarano, G. L., Giacovazzo, C., Polidori, G. \& Spagna, R. (2003). J. Appl. Cryst. 36, 1103.

Enraf-Nonius (1994). CAD-4 EXPRESS. Version 5.1/1.2. Enraf-Nonius, Delft, The Netherlands.

Harms, K. \& Wocadlo, S. (1995). XCAD4. University of Marburg, Germany. Johnson, C. K. (1976). ORTEPII. Report ORNL-5138. Oak Ridge National Laboratory, Tennessee, USA.

Nardelli, M. (1995). J. Appl. Cryst. 28, 659.

Sheldrick, G. M. (1997). SHELXL97. Release 97-2. University of Göttingen, Germany. 